\title{
Super-heróis, história dos quadrinhos e a popularização das ciências
}

\section{Superheroes, history of comics and science popularization}

\author{
Cleber de Souza Filho \\ Programa de Pós-Graduação em História das Ciências e das Técnicas e Epistemologia \\ (HCTE), Universidade Federal do Rio de Janeiro (UFRJ) \\ souza.cbio@gmail.com \\ orcid.org/0000-0003-4634-8646
}

\section{Evandro Vieira Ouriques}

Programa de Pós-Graduação em História das Ciências e das Técnicas e Epistemologia (HCTE), Escola de Comunicação (ECO), Universidade Federal do Rio de Janeiro (UFRJ)

evandro.vieira.ouriques@gmail.com

orcid.org/0000-0003-1000-8447

Resumo. Quadrinhos são vistos como objetos de entretenimento, seja em seu formato original impresso, ou em suas outras mídias como televisão e cinema. Porém, apesar de sua grande popularidade e aceitação hoje, a história dos quadrinhos no ocidente é conturbada por sua relação com profissionais especializados de diversas áreas. A reflexão acerca de suas origens históricas tem o objetivo de resgatar interlocuções com campos do conhecimento para destacar a possibilidade do uso deste objeto como uma forma de linguagem para comunicar, divulgar e popularizar as ciências, observando sua importância histórica e sua relevância na cultura popular atual.

Palavras-chave: História das ciências. Divulgação científica. Quadrinhos.

Abstract. Comics are seen as entertainment objects, either in its original printed format or in its other media, such as television and motion pictures. Despite comics' great popularity and acceptance today, the History of comic books is troubled by its complicated relationship with specialized professionals from different fields, such as psychologists. The inquiry on its historical origins may 
rescue a dialogue between fields of knowledge, highlighting comics' possibility to be used as a form of language to communicate, disseminate and promote science, raising awareness on its historical importance and its relevance in the current popular culture.

Keywords: History of science. Science popularization. Comic books.

Recebido: 01/10/2017 Aceito: 27/10/2017 Publicado: 05/11/2017

\section{Introdução}

Os quadrinhos, sua cultura, seus diversos formatos em diferentes meios de comunicação foram e são entendidos como meros artigos de lazer e entretenimento sem explorar o que suas potencialidades subjetivas, e principalmente o tipo de linguagem usada na formulação desses quadrinhos, podem oferecer para diversas áreas do conhecimento. Dificilmente os quadrinhos são encarados como uma forma de produção artística ou cultural, pois além de não se encaixarem nas formas de artes tradicionalmente préestabelecidas, seu formato de mídia em massa é comumente voltado para e consumido pelo público infanto-juvenil e jovem adulto. Inclusive esse status artístico foi muitas vezes questionado no último século por quadrinhos não serem considerados literatura (KAKALIOS, 2005), ignorando os diferentes tipos de narrativa que utilizam imagens como recurso de linguagem em suas diversas formas artísticas.

Algumas possibilidades foram sugeridas nos últimos anos por profissionais da área de comunicação visual para tentar superar esse tipo de questão, através do valor histórico desses objetos e também utilizando esse tipo de linguagem com obras mais conceituais, artísticas e acadêmicas. A motivação desse esforço pode ser atribuída às inúmeras dificuldades que diversas áreas de conhecimento têm encontrado para melhor comunicar e divulgar seus conteúdos, à recente explosão de popularidade dos quadrinhos, e suas personagens, potencializada pelo cinema nas últimas décadas e principalmente ao interesse de profissionais de diversas áreas que são influenciados pela cultura, forma de linguagem e personagens das histórias em quadrinhos.

ugere-se a identificação do problema e contornos científicos/acadêmicos pré-existentes à sua pesquisa. Idealmente o tópico Introdução deve desenvolver-se de modo a revelar a lacuna a ser respondida, total ou parcialmente, pela pesquisa aqui apresentada, bem como as apostas do autor neste ou naquele caminho através da associação de pesquisas realizadas em diferentes campos do conhecimento, e que estão sendo relacionadas na linha investigativa do presente artigo. 


\section{História das Histórias em Quadrinhos}

É uma tarefa árdua apontar com precisão quem fez a primeira tirinha em quadrinhos, quando e em qual jornal, principal meio de veiculação desse formato no ocidente. Esse desafio na verdade vem, desde a década de 40 , fortalecendo a necessidade de pesquisas e formação de profissionais para estudar esse documento histórico que é a tirinha em quadrinhos e consequentemente os quadrinhos em si.

É possível mapear ao longo da História traços do que hoje é entendido como tirinhas em quadrinhos, que aqui se define como linguagem de justaposição (MCCLOUDS, 1993; SOUSANIS, 2012). Essa justaposição de imagens em quadros sequenciais que "transformam o estático em cinético" indica fluidez de movimento ou passar do tempo dentro da narrativa, acompanhados de linguagem textual, "um balanço entre arte e linguagem" (SOUSANIS, 2012).

Nesse diálogo entre arte e linguagem, surge a revista em quadrinhos justapondo não apenas os dois campos, mas suas contribuições técnicas e particularidades de interpretação e fruição estética para o expectador. Eisner (1999) aponta que tanto as regências de arte (pincelada, simetria, perspectiva etc.) quanto de literatura (enredo, sintaxe, contexto etc.) estão simultaneamente presentes nos quadrinhos, fazendo da leitura deste gênero "um ato de percepção estética e de esforço intelectual" (EISNER, 1999).

Essa linguagem já era utilizada por diversos povos espalhados pelo globo em diferentes contextos com materiais variados e é possível encontrar esses vestígios através de imagens no Japão Feudal com a obra "Genji Monogatari Emaki" do século XII (cerca de 1120-1140), na idade média com a Tapeçaria de Bayeux do século XI (cerca de 1070-1080), na Roma Antiga com a Coluna de Trajano do século II (cerca de 107-113) ou, se forem permitidos aprofundamentos mais criativos, no Livros dos Mortos no Egito (cerca de $2400 \mathrm{AC}$ ) e nas pinturas rupestres pré-históricas das cavernas (cerca de 38.000 AC) (CAMPOS, 2015).

Desde a década de 40 a origem dos quadrinhos no formato contemporâneo é debatida na Europa e nos Estados Unidos. Como coloca Campos (2015), diversos autores de bestsellers, historiadores, jornalistas e entusiastas tentam e tentaram cunhar o grande criador ou pai dos quadrinhos, o primeiro grande autor a lançar uma tirinha amplamente conhecida em um jornal. Esse debate ocorreu como uma tentativa de garantir reconhecimento ou certo status não só para o historiador ou autor do livro sobre o assunto, mas também para quem publicava as tirinhas, para o jornal onde foram publicadas e também o local de origem do jornal e do cartunista.

Em 1996, estabeleceu-se que a tirinha Yellow Kid de 1896 por Richard Fenton Outcault seria cunhada como a primeira obra desse novo meio de comunicação, o que gera problemas porque ignora as contribuições anteriores a essa data por inúmeros autores, inclusive do próprio autor de Yellow Kid (CAMPOS, 2015). 


\section{História dos Super-Heróis}

Os super-heróis dos quadrinhos se tornaram grandes responsáveis pela popularização global dessa forma de comunicação, "uma forma de manifestação da arte produzida nos Estados Unidos e consumida em diferentes partes do mundo" (INGE, 1990; VELOSO, 2002). Entre 1902 e 1933 foram publicadas tirinhas em quadrinhos, pulp fictions,

revistas e apresentações de rádio sobre diversos personagens fantásticos, com poderes sobre-humanos normalmente de origem sobrenatural ou de fíç̧ão científica, despertando uma serialização das obras e grande curiosidade do público por contar histórias místicas de lugares distantes à realidade ocidental.

Inúmeras personagens serviram como fundação para os super-heróis que conhecemos hoje. Alguns exemplos importantes são: Hugo Hercules (entre 1902-1903 no jornal Tribuna de Chicago) por Wilhelm Heinrich Detlev Körner, John Carter de Marte (1911 na revista A Princesa de Marte) por Edgar Rice Burroughs, Tarzã o Homem Macaco (1912 na revista Tarzan dos Macacos) também por Edgar Rice Burroughs, Zorro (1919 na revista All-Story Weekly) por Johnston McCulley, Buck Rogers (1928 na novela Armageddon 2419 A.D. da revista Amazing Stories) por Philip Francis Nowlan, O Sombra (1930 no rádio e 1931 na pulp fiction) por Walter B. Gibson (com pseudônimo Maxwell Grant), O Cavaleiro Solitário (1933 no rádio) por George W. Trendle, Doc Savage - O Homem de Bronze (1933 na revista Doc Savage Magazine) por Lester Dent (com pseudônimo Kenneth Robeson), O Besouro Verde (1936 no rádio) também por George W. Trendle e Fran Striker, O Fantasma (1936 em forma de tirinha) por Lee Falk, O Vingador (1939 na revista O Vingador) e Flash Gordon (1934 em forma de tirinha) por Alex Raymond.

Graças à inspiração dessas personagens, em especial John Carter de Marte e Tarzã - o Homem Macaco, em 1938 é lançado, pela Detective Comics Company na revista Action Comics primeira edição, o super-herói criado por adolescentes de nome Super-Homem (1934) de Jerry Siegel e Joe Shuster, invertendo a relação da narrativa (pela primeira vez não se tratava de um homem desbravando o desconhecido e sim uma personagem extraterrestre vivendo nos Estados Unidos) e revolucionando o universo da ficção científica em quadrinhos. O Super-Homem se tornaria o pontapé inicial para toda uma nova geração de heróis e muitos deles, de alguma forma, acabariam entrando em contato com certos aspectos das ciências ou contextos científicos.

\section{Divulgação Científica e Super-Heróis?}

Existem diversas pesquisas na área de educação informal sobre o uso de diferentes tipos de narrativas e mídias de ficção científica e outros temas como plano de fundo para ensinar e obter melhor entendimento dos princípios científicos. Trabalhos com essa temática têm a intenção de despertar visibilidade para um ponto chave das práticas 
educativas e para divulgação científica, que é a necessidade de aperfeiçoar a linguagem adotada pelos cientistas e professores de ciências a fim de traduzir o conhecimento científico para o público jovem.

Ao longo do século $\mathrm{XX}$ as histórias quadrinhos eram muito acessíveis para o público geral e em especial para crianças e adolescentes por causa do seu preço baixo, construindo uma relação duradoura com o público, apesar de perseguições e estigmas que as histórias em quadrinhos sofrem desde a década de 50 (KAKALIOS, 2005),

como, por exemplo, no livro Seduction of the Innocent (1953) de Fredic Wertham. O escopo dos quadrinhos vem se aperfeiçoando com o passar das décadas, com suas produções artísticas e culturais transmidiáticas que atravessaram os jornais, revistas, rádio, televisão e hoje principalmente através do cinema, da internet, de jogos e dos quadrinhos em si, além de outras mercadorias (brinquedos, materiais escolares, roupas e etc.). Esses objetos demonstram um poder estrutural que influenciam todas as faixas etárias: seus produtos têm grande procura internacional e movimentam bilhões de dólares todos os anos com seus filmes, séries de televisão, parques etc.

O impacto dos quadrinhos na sociedade recente como um agente de diálogo tem sido explorado por alguns pesquisadores das áreas da comunicação visual e da pedagogia, e leva em consideração que as histórias em quadrinhos são produtos de alcance mundial, distribuídos em larga escala em diferentes línguas e se encaixam na definição de Fairclough (1995) para Mídia em massa, pois mediam a relação entre a esfera pública e o domínio privado. As histórias em quadrinhos e suas personagens nascem de uma visão ou representação simplificada do real e foram construídas nas últimas décadas documentando história e criando memórias a partir da relação dos seus autores e suas relações com acontecimentos sociais, históricos, políticos e científicos. É através desse diálogo, do seu alcance e dessas relações que as histórias em quadrinhos têm o potencial de realizar contextualizações necessárias para questões de diferentes campos do conhecimento em sala de aula, usando esses objetos lúdicos para estimular a curiosidade e despertar o interesse dos alunos na construção dos saberes científicos (MESSEDER, 2010).

\section{Considerações Finais}

Sugere-se a realização de uma reflexão teórica sobre o uso de objetos lúdicos da cultura popular, a fim de aproveitar a notoriedade atual dos quadrinhos e todos os seus desdobramentos para promover uma melhor compreensão do conteúdo científico do ensino básico e da popularização da ciência para o público geral. É através dos objetos lúdicos (em suas diversas formas e mídias) que sejam mais próximos da realidade dos alunos que será possível obter maior facilidade para encorajar a curiosidade científica das crianças e adolescentes (MARANDINO, 2004) acerca de diversos temas. E os quadrinhos, por desenvolver conteúdo por mais de 100 anos, em especial quadrinhos de 
super-heróis permeando campos das ciências através da ficção científica nos últimos 70 anos, podem servir como esse objeto lúdico para diferentes áreas de ensino.

\section{Financiamento}

O presente trabalho foi realizado com apoio da Coordenação de Aperfeiçoamento de Pessoal de Nível Superior - Brasil (CAPES) - Código de Financiamento 001.

\section{Referências}

CAMPOS, R. Imageria: o nascimento das histórias em quadrinhos. São Paulo: Veneta, 2015.

EISNER, W. Quadrinhos e Arte Seqüencial. São Paulo: Martins Fontes, 1999

FAIRCLOUGH, N. Media Discourse. Nova Iorque: Edward Arnold, 1995

INGE, M. T. Comics as Culture. Mississipi: University Press of Mississippi, 1990

KAKAliOS, J. The Physics of Superheroes. 2. ed. Nova Iorque: Gotham Books, 2005.

MARANDINO, M. et al.A Educação não formal e a Divulgação Científica: O que pensa quem faz? In: Anais do IV Encontro Nacional de Pesquisa em Ensino de Ciências. Bauru, 2004

MCCLOUD, S. Understanding Comics. Northampton: Kitchen Sink Press, Inc, 1993

MESSEDER, J. C.; RÔÇAS, G. O Lúdico e o ensino de Ciências: um relato de caso de uma Licenciatura em Química Revista Ciências \& Idéias, Rio de Janeiro, v. 1, n. 1, p. 69-75, 2010.

SOUSANIS, N. The shape of our thoughts: A meditation on $\&$ in comics. Visual Arts Research, Illinois: University of Illinois Press, v. 38, n. 1, p.1-10, 2012.

VELOSO, F. O. D. Us vs Them: A critical reading of Superman - Peace on Earth. Dissertação de Mestrado. Florianópolis: UF 